\title{
Empirical Research on the Enterprise Human Resource Management and Its Influences on Strategic Development of Enterprise under the Mass Innovation Background
}

\author{
Lili Lu \\ Xi'an International University; \\ Shaanxi Xi'an 710077 China
}

\begin{abstract}
In this paper, we conduct research on the enterprise human resource management and its influences on strategic development of enterprise under modern mass innovation background. Human resource management involves the enterprise each managers, human resources department should become an enterprise real system of planning, decision-making, design department, focus on to build a good working environment, development potential employees, to improve enterprise efficiency. Try to practice "people-centered" management style, to "medium" in-depth reason. Stand in perspective of others. The realization of self-worth and help subordinates management measures of organizational goals and it is management level of modern management should pursue. With the combination of the modern mass innovation background we achieve the optimized management pattern.
\end{abstract}

Keywords- Human Resource, Strategic Development, Mass Innovation, Empirical Research.

\section{Introduction}

Human resource is the strategic resource of modern enterprise and enterprise development of the key factors, human resource management plays an increasingly important role in the modern enterprise. Modern enterprise management practice site, human resource management is the core member of the modern enterprise management status, how to find the right talent for the enterprise, retain talent and develop talent. For the enterprise to maintain strong vitality and competitiveness to provide the strong support is becoming an important topic for the modern enterprise human resources department.

The modern approaches of enhancing the human resources management pattern could be separated into listed aspects. (1) Create a new human resource management mode. The new model of human resource management to a certain extent and reduce business operating costs and increase profits. The second is management department that can provide paid services through both inside and outside the enterprise to gradually be evolved into a profit center. (2) Do the human resource strategy and basic competitive strategy. Enterprises in determining the human resources development strategy that must first clear business vision and strategy with mark, and then determine human resources development strategy. Human resources strategy as an important part of general strategy of enterprise development, to implement the overall strategy of enterprise development plays a very role. (3) The staff training as a way to solve the talent demand. Enterprises can make full use of national compulsory education, higher education and social support to carry out staff training work, education and other forms should not only pay the attention to the content of the training, and should pay attention to the level of the training. (4) To develop the truly effective incentive mechanism. Incentive mechanism is a corporate human resources development and the management of an important part of it smoothly without the establishment of the company's 
human resources management system framework [1-2].

It is well known that man is the main body of all social economic activities its object is the people and things. So-called management is the subject of the object management, that person to the person's management, and through the management of the people to promote people to content management. Visible to the person's management and the basic management of the content is not parallel, only to strengthen the management of the people and through the management of people as can better realizes the management of the content. If one enterprise can place in the fierce market competition foothold and often depends on its own human resources, however, with the change of competitive environment, the development of market economy, the enterprise human resource management is also put forward higher requirements, human become an enterprise maintain competitive market advantage which has become the important guarantee. The figure one shows the core components [3].

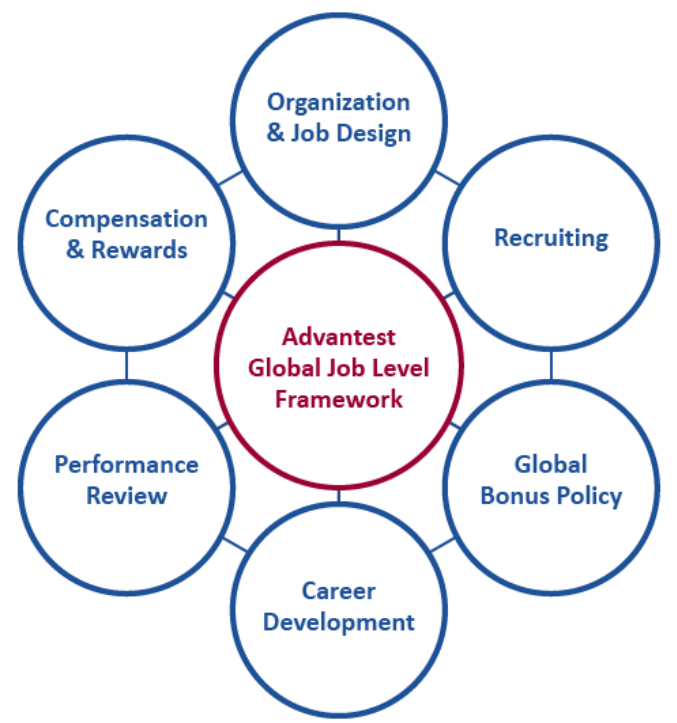

Figure 1. The Principles of the Enterprise Human Resource Management

In this paper, we conduct research on the enterprise human resource management and its influences on strategic development of enterprise under the mass innovation background. Its properties of human resources determine the rules are necessary for the sustainable development of enterprises. It's need to do a good job of development and the utilization of human resources, to ensure the effect of the play, which requires enterprise human resources systematization management, to ensure activation energy, for human resources potential value of digging, so as to satisfy business enterprise market competition need. In the later sections, we will analyze mentioned challenges in detail and provides suggestions.

\section{Our Proposed Methodology}

The Strategic Development of Enterprise. Strategic ecological management model emphasizes the ecological system and relationship resources are the source of enterprise competitive advantage, must integrate the external force to cultivate and promote its core ability, the core competence of play its leverage. No system network support, the core competence of enterprises is difficult to play as more can't realize the creation of the new core competence. Using the theory of strategic ecology system, embedded in the ecosystem of the interactive relation between various network analysis, overcome traditional strategy from the enterprise external industry analysis or only from the defect of enterprise core competence analysis, ensure enterprise ability of internal and external to the benign interaction to maximize the corporate social value [4-5].

The complex uncertainty enterprise internal and external factors bring a series of risk to corporate strategy, often makes the enterprise strategic target can't reach, and even make enterprise. Strategic risk is the enterprise is unable to avoid the reality of the problem, must be managed, who better solved the problem of strategic risk management, who will be able to obtain a new competitive advantage. The following aspects are the principles that we should take into consideration. 
- Set up the ideas of strategic management. We must set up the consciousness of the enterprise long-term development, although the small and medium-sized enterprises facing difficulties such as financing, marketing, innovation, but if we have a good business strategy, reasonable planning for enterprise resources to solve various difficulties and realize its own survival and the long-term development goal is quite helpful [6].

- A strategic choice. In the clear enterprise's position in the competition and its own advantages and disadvantages, choose suitable development strategy for the enterprise itself, to establish their own characteristics can be in a better position to make the enterprise in the competition.

- Strategic assessment and the control. Mostly family-owned enterprises of the medium-sized enterprises in China, in an atmosphere of affection, enterprise strategy implementation cannot thoroughly. To ensure the implementation of the strategy of enterprise must have a standard of assessment and the monitoring system. First of all, to establish the standard of monitoring, including qualitative and quantitative evaluation standard. Second, in the practical work of the strategy implementation and monitoring standard carries on the analysis comparison. Once again to find out the deviation and the causes of deviation and adopt corresponding measures.

\section{The Human Resource Management.} Enterprise human resource management can motivate the employees to work of energy and power, an employee in enterprise's value and to achieve self-worth, implementation staff sense of achievement and satisfaction to enterprise. Under the market economy environment, enterprises gradually pay attention to the importance of human resource management in enterprise management, through introduction of new management idea and mechanism to constantly promote the scientific and standardization level of the human resources.

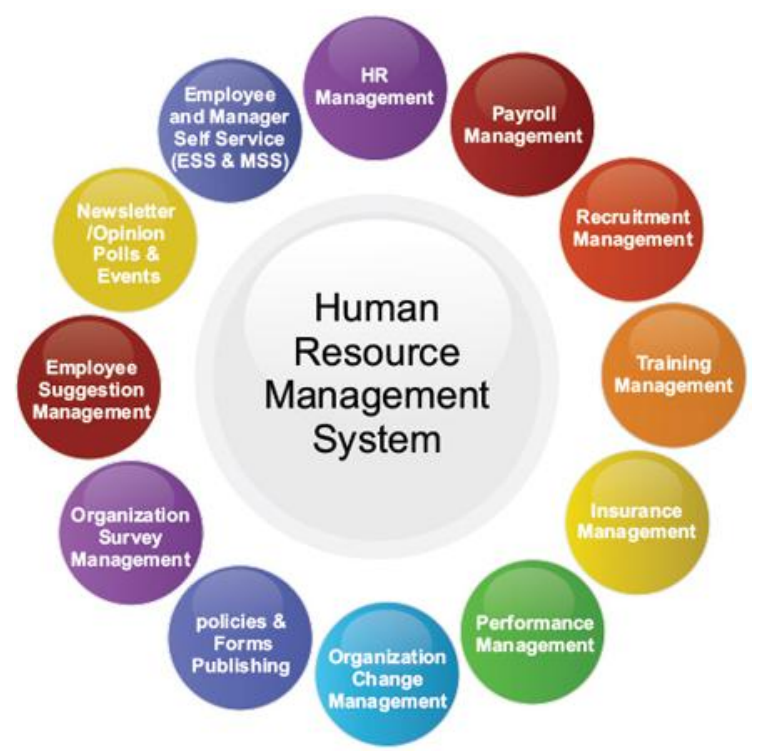

Figure 2. The Components of the Human Resource Management System

Communication mechanism in human resources management should be embodied in the employee into the company to leave the company this process, so contained in communication, communication during work, job change of communication and the communication from the construction company before, in addition from the current in the phenomenon of the poor communication as we can see, the transition of idea is also very important, so before establishing perfect communication mechanism, to cultivate the consciousness of managers and by the managers communication and pay attention to the communication activities. Because the essence of the strategy is to achieve organizational goals in a certain environment and use resources strategy, human resource is the most to resources as enterprise competition is the most promising for the enterprise development of the investment. Nature of human resource management become 
the most decisive opinion content about enterprise management, the status of human resource management department also rise as a strategic sector [7].

Accordingly, we should follow the listed countermeasures. (1) Establish humanist management idea. Enterprise's competition in the final analysis is competition. Therefore, private enterprises to establish "people-oriented" management idea, is to carry out all work people-centric, regard people as enterprise's most dynamic and most dynamic and creative first resources. (2) Establish an objective and fair performance evaluation system. Performance evaluation is an important part of the enterprise human resources management and it is closely associated with human resource management of each work. (3) Build system of education and training, and constantly improve the quality of employees as private enterprises to increase investment in education and training, knowledge and skill training of the employees on a regular basis. (4) To strengthen the construction of enterprise culture. Enterprise culture is the spirit of an enterprise, is the social image of an enterprise is the enterprise reputation and is the enterprise survival and development.

The Mass Innovation Background. Mass innovation entrepreneurship is a new way of the basic innovation of industrial organization. As the Internet, such as open source technology platform is open to public entrepreneur popularization, the individual can become organization configuration of the industry resources, since the decentralized organization production began to appear, thus promote the traditional mass production gradually to develop in the basic direction of flexibility, intelligence, specialization, on-demand scale of production while the customization is becoming reality.

Open social network users are an important role in ecological, as industry directly involved in the product conception, design, manufacture, improvement, and entrepreneurs to communicate product ideas with experience and personality needs. Innovative undertaking is conducive to meet the demand of the highest of the masses as the Maslow's hierarchy of needs to self-actualization as the highest requirements. Rapid economic development of the basic satisfy people's material life needs and by creating more and more people are needed to meet the needs of self-actualization. Public venture, all fundamental goals is to meet the demands of life for the people to create and realize the life value of the development channel, let the spirit of independent development become more common among the people that let every cell of society holds a positive mental attitude and the spirit of excellence.

The Enterprise Innovation. Integration of technological innovation mode and system integration and the emergence of the network model makes our understanding of the nature of innovation have an innovation is a process of interaction of the network. Because of the complexity of the innovation and uncertainty while the market increasingly competitive, increasingly shorter product production cycle, makes any enterprise impossible within it all get all the knowledge and information, enterprises are also difficult to include full value chain of innovation activities in the internal. In order to innovation, enterprises have to contact other organizations to produce [8].

Mature enterprise innovation network by forms of leasing, and the informal communication on its innovation needed elements integration, obtained the spillover effect, breaking the technical barriers, to reduce the risk of innovation, avoid the high market transaction costs, become solve the problem of the fast changing market environment technology innovation a best model. The so-called knowledge has the branch of explicit and implicit, explicit knowledge refers to codify knowledge while these knowledge easily with hard data, scientific formula, coding transmission and sharing in the form of application or universal principle. Tacit knowledge refers to knowledge, 
difficult to standardization and coding consists of the image concepts, ideas, beliefs and perception, highly exclusiveness. The so-called technology may be the same technology can also be complementary and mutual benefit.

The core competence of enterprises is the core of the enterprise comparative advantage, it is the enterprise in the long-term accumulated in the process of operation, technology is not a decentralised or skills, but a skill or basic technique integration, in essence is an aggregate of a capability, but the enterprise core competence is not necessarily cutting-edge science and technology and its application, it can be widely exist in all walks of life. The accumulation and development of core competence is the cornerstone of the foundation of the enterprise competitive advantage. Design with relationship of the market and its design known as the driver of product innovation, as a design driven marketing innovation, in the coupling type enterprise, the status of China in the design, not only influence the innovation of the technology factor, system factor organization elements and marketing also profound influence that will be in the coupling type enterprise and this feature is especially prominent.

\section{Conclusion}

In this paper, we conduct research on the enterprise human resource management and its influences on strategic development of enterprise under mass innovation background. In practice, the integrated model of an enterprise is always easy to imitate, such as enterprise in the production operation system, the pattern of financial management system, quality control system of easy to imitate by competitors, thus resulting in a loss of its competitive advantage. Relative to the work mode, enterprise human resources management model is not easy to imitate that is because the enterprise human resources systematization management involves a series of activities, the ability of the ability of the enterprise, through the systematic management of human resources which can effectively improve the system of application benefit. Different practical activities of human resource management is connected with each other is an interconnected organic system and the activities of human resource practices other developing must practice. Our research combines the advantages of the mass innovation background to form the novel human resources management pattern that is innovative.

\section{References}

[1] Bal, P. Matthijs, and Annet H. De Lange. "From flexibility human resource management to employee engagement and perceived job performance across the lifespan: A multisample study." Journal of Occupational and Organizational Psychology 88.1 (2015): 126-154.

[2] Harrington, Susan, Samantha Warren, and Charlotte Rayner. "Human Resource Management practitioners' responses to workplace bullying: Cycles of symbolic violence." Organization 22.3 (2015): 368-389.

[3] Lu, Chia-Mei, et al. "Effect of diversity on human resource management and organizational performance." Journal of Business Research 68.4 (2015): 857-861.

[4] Boon, Corine, et al. "Perceived Human Resource Management Practices." Journal of Personnel Psychology (2015).

[5] Thomas, Kenneth D. "Molluscs emergent, Part II: themes and trends in the scientific investigation of molluscs and their shells as past human resources." Journal of Archaeological Science 56 (2015): 159-167.

[6] Sakalas, Algimantas, and Milita Vienazindiene. "New public management and the conceptual upheaval of human resource management." Engineering Economics 21.4 (2015). 
[7] Pulakos, Elaine D., et al. "Performance management can be fixed: An on-the-job experiential learning approach for complex behavior change." Industrial and Organizational Psychology 8.01 (2015): 51-76.
[8] Brown, Christopher. "Scale and subnational resource management: Transnational initiatives in the Salish Sea Region." Review of Policy Research 32.1 (2015): 60-78. 